\title{
Congenital cystic eye with multiple dermal appendages: a case
} report

\author{
Pankaj Gupta*†1, Krishna Pal Singh Malik ${ }^{\dagger 2}$ and Ruchi Goel ${ }^{\dagger 3}$
}

\begin{abstract}
Address: ${ }^{1}$ Senior Resident, Department of Ophthalmology Vardhman Mahavir Medical College New Delhi 110029 India, ${ }^{2}$ Consultant and Head, Department of Ophthalmology Vardhman Mahavir Medical College New Delhi 110029 India and 3Senior Resident, Department of Ophthalmology Vardhman Mahavir Medical College New Delhi 110029 India

Email: Pankaj Gupta* - itsdrpankaj@hotmail.com; Krishna Pal Singh Malik - malikkps@rediffmail.com; Ruchi Goel - gruchi1@rediffmail.com

* Corresponding author †Equal contributors
\end{abstract}

Published: 03 July 2003

BMC Ophthalmology 2003, 3:7
Received: 06 February 2003

Accepted: 03 July 2003

This article is available from: http://www.biomedcentral.com/147/-24/5/3/7

(C) 2003 Gupta et al; licensee BioMed Central Ltd. This is an Open Access article: verbatim copying and redistribution of this article are permitted in all media for any purpose, provided this notice is preserved along with the article's original URL.

\begin{abstract}
Background: A partial or complete failure in the involution of the primary optic vesicle resulting in the formation of a cyst is an extremely rare anomaly known as congenital cystic eye. The primary optic vesicle is formed but instead of the anterior part of the vesicle involuting to lie in apposition with the posterior part, a cyst persists at birth and replaces the eye.

Case Presentation: We report a case of congenital cystic eye associated with multiple dermal appendages in a I-day-old female child. This condition presented at birth as a large orbital mass in the left orbit that bulged forwards and stretched the eyelids. No globe or any other ocular structures were identified in the orbit. Multiple dermal appendages were present in the adjacent part of the face below the left orbit and on the upper part of the neck.

Conclusions: Congenital cystic eye is an extremely rare condition and with only 28 previous cases reported in the literature. We present the second case of congenital cystic eye with multiple dermal appendages of the face and neck.
\end{abstract}

\section{Background}

A partial or complete failure in the involution of the primary optic vesicle resulting in the formation of a cyst is an extremely rare anomaly. The primary optic vesicle is formed but instead of the anterior part of the vesicle involuting to lie in apposition with the posterior part, a cyst persists at birth and replaces the eye. The size of the cyst is variable. The condition has also been called anophthalmos with cyst in the literature. The term congenital cystic eye was coined by Mann [1] to describe a case of this rare ocular malformation. The failure in invagination of the primary optic vesicle occurs between the $2 \mathrm{~mm}$ and $7 \mathrm{~mm}$ stage of fetal development [2]. The exact aetiology of congenital cystic eye remains unknown. We in this study present a 1-day-old infant with congenital cystic eye associated with multiple skin tags.

\section{Case Presentation \\ Case Report}

A 1-day-old female child presented with a large mass in the left orbital region and multiple skin appendages on the face and upper part of neck on the left side. The child was born to nonconsangineous parents and was the product of a full term vaginal delivery. The pregnancy and labour were uncomplicated. The baby had a birth weight of $2.7 \mathrm{~kg}$. The baby had normal reflexes for age and had no respiratory distress. 
Examination disclosed a large erythematous mass that virtually filled the entire left orbit (fig. 1). The lower eyelid was obscured by the swelling, the upper eyelid was stretched, and the eyebrow was also displaced upwards. The skin of the eyelids was normal. The mass was soft, cystic in consistency, translucent, nontender, nonpulsatile, nonreducible and the size of the mass was not related to crying. Examination disclosed no identifiable globe. The right eye was normal. The patient also had multiple dermal appendages on the face inferotemporal to the left orbit (fig. 1) in addition to 1 appendage present just anterior to the tragus of the ear and an appendage present on the upper part of the neck. The appendages measured 5$10 \mathrm{~mm}$ in size, were nontender and were covered by normal skin.

The laboratory workup was unremarkable. Roentgenograms of the skull disclosed symmetrical enlargement of the left orbit with a soft tissue shadow. The intracranial features were normal and no radiologic evidence of encephalocoele or meningocoele was present. Computed tomography of the head and orbits disclosed a mass in the left orbit that was predominantly hypodense and cystic. The left orbit was larger in size than the right orbit. No identifiable globe, optic nerve, extraocular muscles or any other orbital structure were present (fig. 2). The intracranial cavity was normal with normally developed brain parenchyma, corpus callosum and ventricles. Based upon the above findings, a diagnosis of congenital cystic eye was made.

The patient underwent surgery at the age of 14 days. An anterior orbitotomy approach was used to excise the orbital mass while preserving the eyelids. The cystic mass was removed in toto and measured $4 \times 3 \times 3.5 \mathrm{~cm}$ in size. An orbital implant was also placed in the orbit keeping the future orbital growth in mind. The facial appendages were also excised along with the orbital mass. No identifiable ocular structures or optic stalk were present. The posterior most part of the mass was firm while the majority of the mass was cystic in nature. Histologic examination disclosed multilocular cyst with an outer wall of fibrous tissue and an inner wall of disorganized neural tissue. No ocular structure could be made out. Absence of optic stalk was also confirmed. Examination of the facial dermal appendages disclosed normal epidermal and dermal elements. No cartilaginous or bony structures were present in the appendages.

\section{Discussion}

Cystic orbital lesions account for approximately 10-30\% of all nonthyroid orbital lesions [3]. Congenital cystic eye is the rarest cystic orbital lesion. Duke-Elder reviewed the literature from 1880-1960 and found only 16 cases that he believed represented congenital cystic eye. Since his review, 12 additional cases have reported in the English literature [3]. Congenital cystic eye is thought to result from noninvagination of the primary optic nerve vesicle between the $2 \mathrm{~mm}$ and $7 \mathrm{~mm}$ stages of the embryonic development, and ectodermal elements do not develop into the future eye structures. The orbit thus contains a cyst instead of an eye. The cyst is usually completely filled by proliferating glial tissue. In contrast, a discontinuation in development between the $7 \mathrm{~mm}$ and $14 \mathrm{~mm}$ stage of embryonic development leads to formation of the more common coloboma.

Although the exact aetiology of congenital cystic eye is not known, the frequent presence of inflammatory cells in the cyst suggests an inflammatory cause [2]. No hereditary tendencies have been noted. No abnormalities during pregnancy or perinatal period have been described. The ectodermal elements are not able to develop into the future eye structures. The orbit thus contains a cyst instead of an eye. The cyst is usually completely filled by proliferating glial tissue. Congenital cystic eye is usually unilateral, however 2 cases of bilateral congenital cystic eyes have been reported $[4,5]$. Although the fellow eye in cases of unilateral cystic eye is usually normal, a case of micropthalmia with cyst [6] and persistent hyperplastic primary vitreous [7] each have been reported in the literature.

Congenital cystic eye needs to be differentiated from micropthalmia with cyst. Micropthalmia with cyst develops from incomplete closure of the fetal cleft that results in a cyst attached to the sclera [8]. The eyes are micropthalmic and frequently have uveal, retinal and lens colobomas. The cysts with micropthalmia are usually located in the inferior orbit and cause the lower eyelid to bulge. In contrast, congenital cystic eye usually causes bulging of the upper eyelid.

The cyst associated with congenital cystic eye may vary in size and may have an attached stalk. The patency of the stalk, if present, is associated with the size of the cyst. If the stalk is patent, the size of the cyst remains small due to communication of the cyst with the cranial cavity as described by Hevelston and coworkers in a case report [9]. No stalk was identified in the present case. The cysts are usually single but multiple cysts have been reported by Pillai and coworkers [10]. Congenital cystic eye may be associated with normal or abnormal extraocular muscles although no extraocular muscles were present in the case described in this report. Although the eyelids are usually normally developed, eyelid abnormalities have been reported. Rice and coworkers [11] reported a case of congenital cystic eye with accessory limb of the lower eyelid. The accessory limb of the lower eyelid was attached to the maxilla with a bony joint with cartilages. The limb itself contained striated muscle, fat, areolar tissue and skin and 


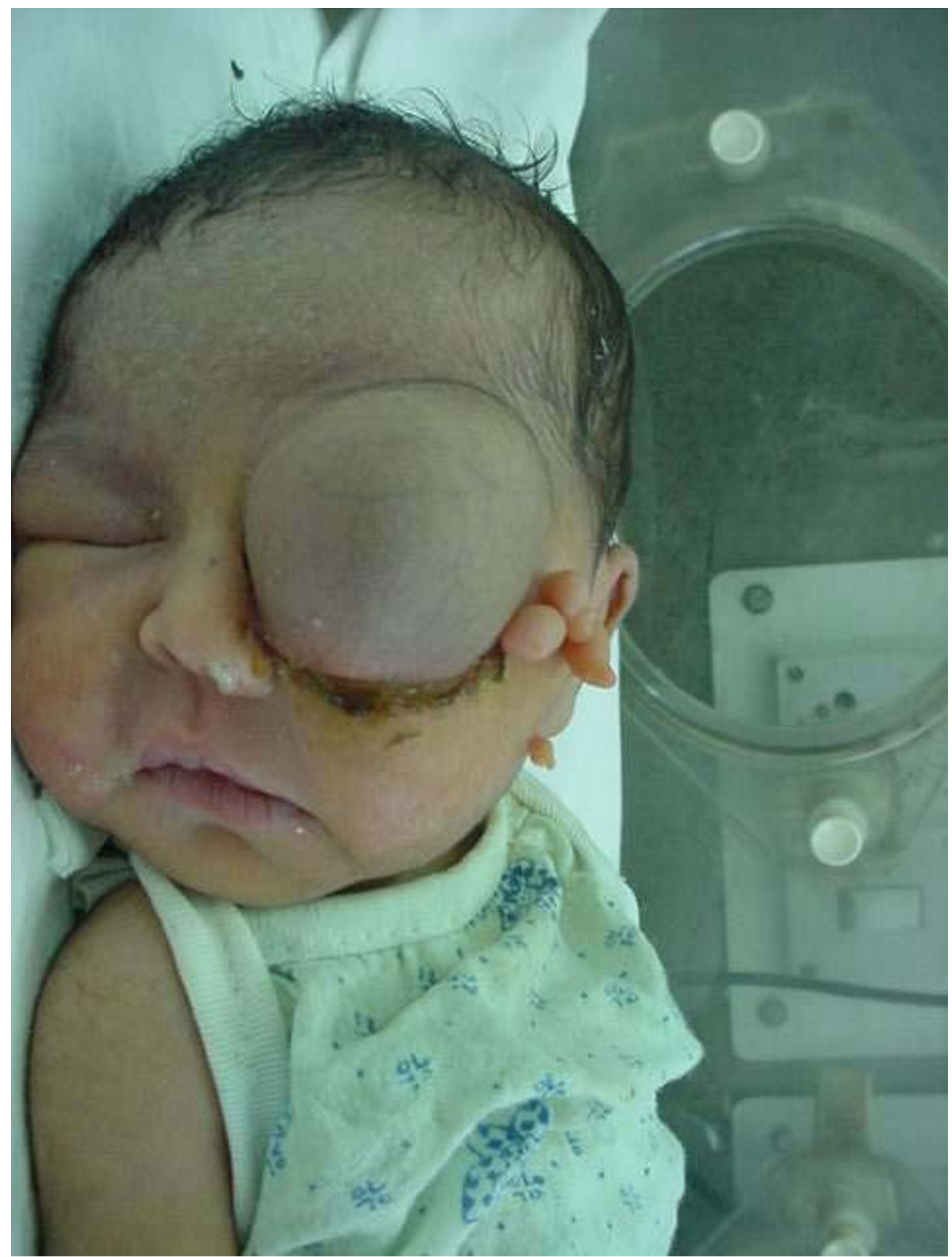

Figure I

Clinical photograph of the patient showing the large mass in the left orbit stretching the upper eyelid along with multiple dermal appendages on the face. 


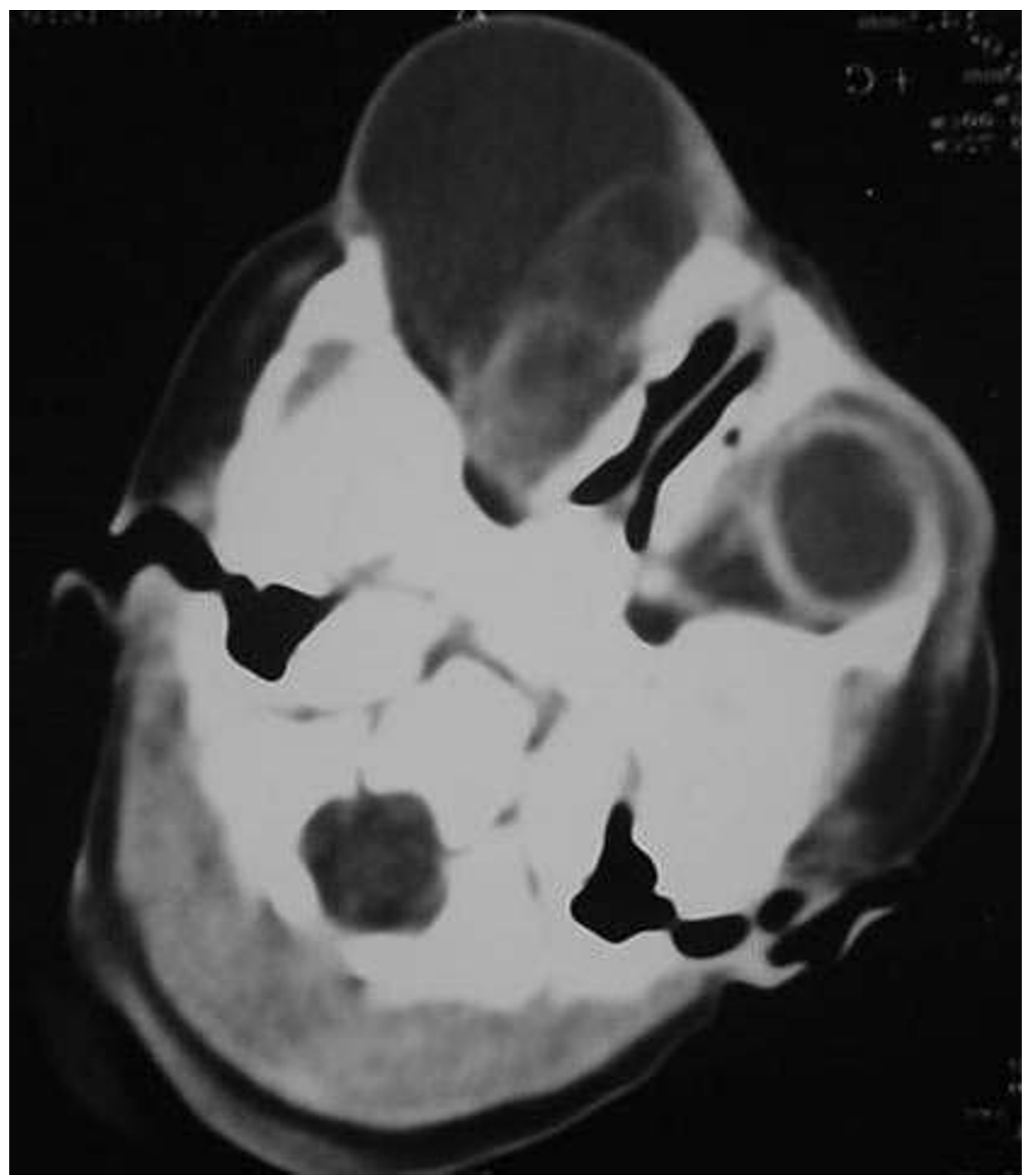

Figure 2

CT scan of the orbits of the same patient showing the large cystic mass in the left orbit. The right eye appears normal. 


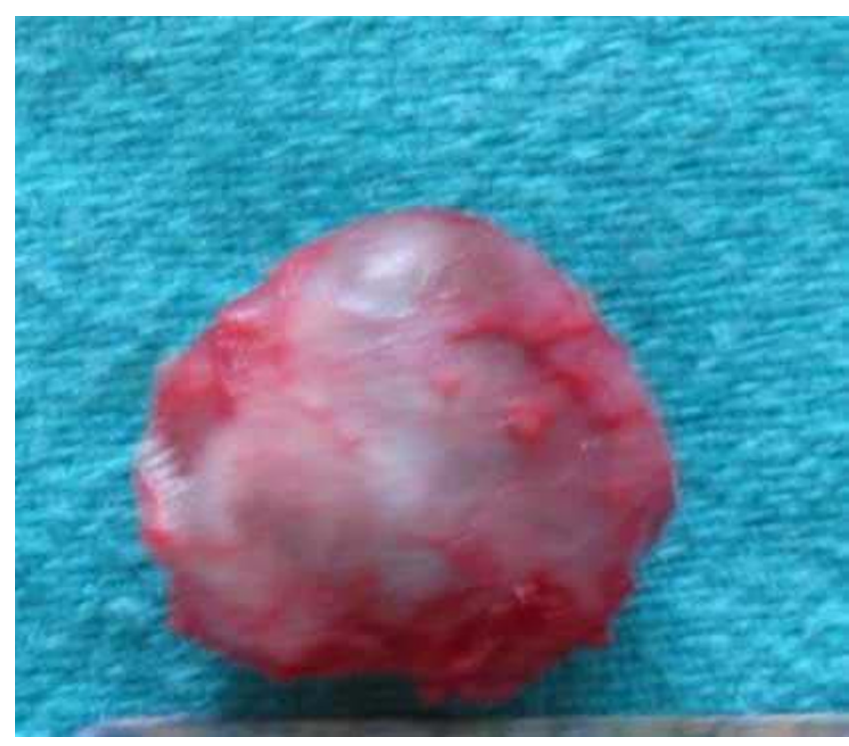

Figure 3

Clinical photograph of the cyst after surgical excision.

had 2 nipple-like and 1 finger-like projections from its surface. Dollfus and coworkers [12] reported a case of congenital cystic eye associated with skin tags. The skin tags were 3 in number and were present near the inner canthus and at the root of nose. Pasquale and coworkers [7] presented a case of congenital cystic eye that was associated with multiple periocular dermal appendages that were present at the lateral aspect of the left upper eyelid. The patient described in this report had multiple dermal appendages that were similar to the ones reported by Pasquale and coworkers. However, the appendages were more numerous and were present on the face and upper part of the neck. This case thus represents the second case of congenital cystic eye associated with multiple dermal appendages.

Other nonocular abnormalities have also been reported in association with congenital cystic eye. These include facial clefting, saddle nose, nostril malformation, choanal atresia, malformation of the sphenoid bone, multiple punched out lesions of the face and scalp, agenesis of the corpus callosum, basal encephalocoele, midbrain deformities, microphallus with hydrocoele, hypoconvex fingernails on short stubby fingers and bifid thumb [3-6]. The case reported here was associated with no such systemic abnormality.

\section{Conclusions}

Congenital cystic eye is usually evident at birth and has a varied presentation. A high degree of suspicion and knowledge about the varied presentations of this condi- tion, and coordinated efforts by Ophthalmologists and Pediatricians are needed for its early recognition and appropriate treatment.

\section{List of abbreviations}

CT scan - Computed Tomography scan.

\section{Competing Interests}

None declared.

\section{Authors' contributions}

All authors have contributed to this case presentation equally.

\section{Acknowledgements}

Written consent was obtained from the patient's relatives for publication of the patient's details.

\section{References}

I. Mann I: A case of congenital cystic eye Trans Ophthalmol Soc Aust 1939, $1: 120-4$.

2. Duke-Elder S: Normal and abnormal development: congenital deformities In: System of Ophthalmology Volume III. Issue Part 2 Edited by: Duke-Elder S. London Henry Kimpton; 1963:45I-3.

3. Hayashi N, Repka MX, Ueno H, lliff NT and Green WR: Congenital cystic eye: Report of two cases and review of literature Surv Ophthalmol 1999, 44:173-9.

4. Goldberg SH, Farber MG and Bullock JD et al.: Bilateral congenital ocular cysts Ophthalmic Paediatr Genet I99I, I 2:31-8.

5. Sacks JG and Lindenberg R: Efferent nerve fibres in the anterior visual pathways in bilateral congenital cystic eyeballs $A m$ J Ophthalmol 1969, 68:691-5.

6. Waring GO III, Roth AM and Rodrigues MM: Clinicopathologic correlation of micropthalmos with cyst Am J Ophthalmol 1976, 82:7I4-2I.

7. Pasquale LR, Romayananda M and Kubacki J et al:: Congenital cystic eye with multiple ocular and intracranial anomalies Arch Ophthalmol 1991, 109:985-7.

8. Mann I: Developmental abnormalities of the eye secondth edition. Philadelphia, JB Lippincott; 1957.

9. Hevelston EM, Malone E Jr and Lashmet MH: Congenital cystic eye Arch Ophthalmol 1970, 84:622-4.

10. Pillai AM, Rema and Sambasivan M: Congenital cystic eye - A case report with CT scan Ind J Ophthalmol 1987, 35(2):88-91.

II. Rice NS, Minwalla SP and Wania JH: Case of congenital cystic eye and accessory limb of the lower eyelid Br J Ophthalmol 1966, 50:409-I3.

12. Dollfus MA, Marx $\mathrm{P}$ and Langlois J et al.: Congenital cystic eyeball Am J Ophthalmol 1968, 66:504-9.

\section{Pre-publication history}

The pre-publication history for this paper can be accessed here:

http://www.biomedcentral.com/1471-2415/3/7/prepub 